\title{
Determination of Cadmium and Lead in Human Teeth Samples by Cloud Point Extraction Preconcentration and Inductively Coupled Plasma Optical Emission Spectrometry
}

\author{
Chunyan Zhang ${ }^{\mathrm{a}}$, Yining Wang ${ }^{\mathrm{a}}$, Xiangrong Cheng ${ }^{\mathrm{a}}$, Haibin Xia $^{\mathrm{a} *}$, and Pei Liang ${ }^{\mathrm{b} *}$ \\ ${ }^{a}$ Key Laboratory of Oral Biomedicine of the Ministry of Education, \\ School \& Hospital of Stomatology, Wuhan University, Wuhan 430079, P.R. China \\ b Key Laboratory of Pesticide \& Chemical Biology of Ministry of Education, College of Chemistry, \\ Central China Normal University, Wuhan 430079, P.R. China
}

\section{INTRODUCTION}

Environmental contamination from heavy metals has been a matter of great concern in many countries for several decades. Human exposure to such elements may cause adverse health effects. Cadmium $(\mathrm{Cd})$ and lead $(\mathrm{Pb})$ have no known physiological functions and are toxic even at low concentrations, leading to neurological defects, renal degradation, bone lesions, and hypertension (1). The best bioindicator for tracing $\mathrm{Cd}$ and $\mathrm{Pb}$ is teeth because these elements accumulate mainly in calcified tissues such as teeth and bones. Moreover, teeth are used as important indicators of environmental toxicology and are excellent vehicles for monitoring pollution in both recent and ancient times (2). Teeth are also a readily accessible biological tissue for analysis $(3,4)$.

Although inductively coupled plasma optical emission spectrometry (ICP-OES) is a powerful analytical tool for the determination of trace elements, the determination of heavy metals in calcium-rich materials such as teeth and bones is not an easy task due to low levels present and strong matrix interferences (5). In ICP-OES, interferences caused by calcium and other alkali earth metals were observed to be

\footnotetext{
*Corresponding autbor. H.B. Xia, E-mail address: xhaibin@wbu.edu.cn, P. Liang, E-mail address: liangpei@mail.ccnu.edu.cn
}

\begin{abstract}
Cloud point extraction was applied as a preconcentration step prior to the determination of cadmium and lead in human teeth samples by inductively coupled plasma optical emission spectrometry (ICP-OES). After complexation with 1-phenyl-3methyl-4-benzoyl-5-pyrazolone (PMBP), the analytes were quantitatively extracted to and concentrated in the phase rich in the surfactant Triton X-114, then measured by ICP-OES. The parameters affecting the extraction efficiency, such as the $\mathrm{pH}$ of the solution, concentration of PMBP and Triton $\mathrm{X}-114$, equilibration temperature and time, were investigated.

Using optimum conditions, the detection limits were 0.83 and $1.48 \mathrm{ng} \mathrm{mL}^{-1}$ for cadmium and lead with relative standard deviations of $2.7 \%$ and $3.8 \%$, respectively $(n=11)$. Verification of the accuracy of the method was carried out by analysis of a standard reference material (NIST 1486 Bone Meal). The method was successfully applied to the determination of trace amounts of cadmium and lead in human teeth samples with satisfactory results.
\end{abstract}

considerable and often led to overor under-estimation of analyte concentrations. To overcome or reduce matrix effects, different calibration methods such as external calibration, matrix-matched calibration standards, standard addition, and internal standards have been proposed. Matrix-matched calibration is often not possible due to unknown or changing sample composition as is the case for some minerals. The use of an internal standard should be specific for many analytes due to the dependence of matrix effect magnitude on spectral line properties $(6,7)$. Therefore, an initial sample pretreatment for matrix separation and analyte preconcentration is often necessary.

Separation and preconcentration based on cloud point extraction (CPE) is becoming an important and practical application of surfactants in analytical chemistry $(8,9)$. The technique is based on the ability of most non-ionic surfactants in aqueous solutions to form micelles and to separate into a surfactantrich phase of small volume and a diluted aqueous phase when heated to a temperature known as the cloud point temperature. The small volume of the surfactant-rich phase obtained with this methodology permits the design of extraction schemes that are simple, inexpensive, highly efficient, speedy, and of lower toxicity to the environment than those extractions that use organic solvents. The cloud point methodology has been used to separate and preconcentrate organic compounds prior to their determination in hydrodynamic analytical systems such as liquid chromatography (10) and capillary electrophoresis (11). The phase separation phenomenon has also been used for the extraction and preconcen- 
tration of metal ions after the formation of slightly water-soluble complexes $(12,13)$. CPE as a preconcentration step in conjunction with spectrophotometry, flow injection analysis (FIA) spectrofluorimetry, flame atomic absorption spectrometry (FAAS), electrothermal atomic absorption spectrometry (ETAAS), ICP-OES, and high performance liquid chromatography (HPLC) for the determination of various metal ions has been widely studied (14-20).

The aim of this work was to combine CPE with ICP-OES and develop a new method for the determination of trace amounts of $\mathrm{Cd}$ and $\mathrm{Pb}$ in human teeth samples. In this method, 1-phenyl-3-methyl-4benzoyl-5-pyrazolone (PMBP), which forms complexes with more than $\mathbf{4 0}$ metal ions and has found numerous applications in trace element separation and preconcentration by solvent extraction $(21,22)$ and solid phase extraction $(23,24)$, was selected as the chelating reagent. The main factors affecting cloud point extraction of $\mathrm{Cd}$ and $\mathrm{Pb}$ were evaluated and optimized. The method was successfully applied to the determination of trace amounts of $\mathrm{Cd}$ and $\mathrm{Pb}$ in human teeth samples.

\section{EXPERIMENTAL}

\section{Instrumentation}

An Optima ${ }^{\mathrm{TM}} 2000$ DV inductively coupled plasma optical emission spectrometer (PerkinElmer, Inc,, Shelton, CT, USA) was used for all determinations. A cyclonic spray chamber and a Gem-Cone ${ }^{\mathrm{TM}}$ nebulizer were used for this work. The operating conditions and wavelengths of the emission lines are summarized in Table I. The $\mathrm{pH}$ values were measured with a Mettler Toledo 320-S pH meter (Mettler Toledo Instruments Co., Ltd., Shanghai, P.R. China). A Model 0412-1 centrifuge (Shanghai Surgical Instrument Factory, Shanghai,
P.R. China) was used to accelerate the phase separation.

\section{Standard Solutions and Reagents}

Stock standard solutions (1000 $\mu \mathrm{g} \mathrm{mL} \mathrm{m}^{-1}$ ) of $\mathrm{Cd}$ and $\mathrm{Pb}$ were obtained from the National Institute of Standards (Beijing, P.R. China). Working standard solutions were obtained by appropriate dilution of the stock standard solutions. The non-ionic surfactant Triton ${ }^{\circledR}$ X-114 was obtained from Sigma-Aldrich (St. Louis, MO, USA) and was used without further purification. A $1.0 \times 10^{-2} \mathrm{~mol} \mathrm{~L}^{-1}$ solution of PMBP was prepared by dissolving appropriate amounts of this reagent in absolute ethanol from the commercially available product (Shanghai ZhenXing First Chemical Factory, Shanghai, P.R. China).

The following buffers were used to control the $\mathrm{pH}$ of the solutions: sodium acetate-acetic acid $(\mathrm{pH}$ 3-6), ammonium acetate-ammonia (pH 6-8), and ammonium chlorideammonia (pH 8-10). All other reagents were of analytical reagent grade or better. Doubly distilled water was used throughout the study. The pipettes and vessels used for trace analysis were kept in $10 \%$ nitric acid for at least 24 hours and subsequently washed four times with doubly distilled water.

\section{Procedures}

For CPE, a 10-mL solution containing the analytes, Triton X-114, and PMBP buffered at a suitable $\mathrm{pH}$ were kept in a thermostatic bath at $40{ }^{\circ} \mathrm{C}$ for 15 minutes; the surfactant-rich phase settled through the aqueous phase. Phase separation was accelerated by centrifugation at $3000 \mathrm{rpm}$ for 5 minutes. After cooling in an ice-bath, the surfactant-rich phase became viscous and was retained at the bottom of the tube. The aqueous phases can readily be discarded simply by inverting the tubes. In order to decrease the viscosity and to facilitate sample handling prior to the ICP-OES assay, $0.5 \mathrm{~mL} 0.1 \mathrm{~mol} \mathrm{~L}^{-1} \mathrm{HNO}_{3}$ was added to the surfactant-rich phase. The final solution was introduced into the nebulizer of the spectrometer by conventional aspiration. Calibration was performed against aqueous standards and submitted to the same CPE procedure. A blank (doubly distilled water without $\mathrm{Cd}$ and $\mathrm{Pb}$ ) was submitted to the same procedure as described above and measured parallel to the samples and calibration solutions.

\section{Preparation of Samples}

Portions (1.0000 g) of certified reference material (CRM) NIST 1486 Bone Meal (National Insitute of Standards and Technology, Beijing, P.R. China) were transferred into PTFE beakers, and $10 \mathrm{~mL}$ of concentrated $\mathrm{HNO}_{3}$ and $2 \mathrm{~mL}$ of

TABLE I

\section{ICP-OES Operating Conditions and Wavelengths of Emission Lines Examined}

\begin{tabular}{lr}
\hline Parameters & \\
\hline RF power & $1.1 \mathrm{~kW}$ \\
Plasma gas (Ar) flow rate & $15 \mathrm{~L} \mathrm{~min}^{-1}$ \\
Auxiliary gas (Ar) flow rate & $1.0 \mathrm{~L} \mathrm{~min}^{-1}$ \\
Nebulizer gas (Ar) flow rate & $0.5 \mathrm{~L} \mathrm{~min}^{-1}$ \\
Pump flow rate & $0.8 \mathrm{~mL} \mathrm{~min}^{-1}$ \\
Observation height & $15 \mathrm{~mm}$ \\
Wavelength & $\mathrm{Cd} 228.802 \mathrm{~nm} ; \mathrm{Pb} \mathrm{220.353} \mathrm{nm}$ \\
\hline
\end{tabular}




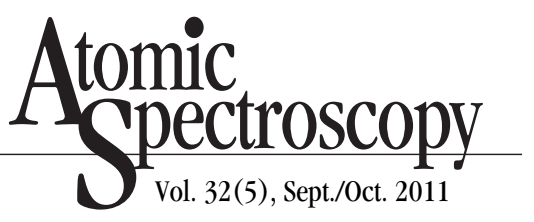

$\mathrm{H}_{2} \mathrm{O}_{2}$ were added. The solutions were then continuously heated to near dryness. The residue was dissolved in $0.1 \mathrm{~mol} \mathrm{~L}^{-1} \mathrm{HCl}$ and made up to 50-mL volume with water.

Noncarious and intact human permanent teeth samples were obtained from patients at the School of Stomatology, Wuhan University, Wuhan, P.R. China. Informed consent was obtained from the patients. This study was approved by the Ethics Committee of School of Stomatology, Wuhan University. After extraction, the teeth were cleaned with a polyethylene scraper and rinsed with a saline solution. The teeth were ultrasonically rinsed with doubly distilled water for 1 hour, dried at $110^{\circ} \mathrm{C}$ for 24 hours, and ground to 100 mesh with an agate mortar. Then the digestion procedure mentioned above was applied to the samples.

\section{RESULTS AND DISCUSSION}

\section{Effect of pH on CPE}

Formation of the metal-chelate and its chemical stability are two important influences for CPE. The $\mathrm{pH}$ plays a unique role on metalchelate formation and subsequent extraction and has proven to be the main parameter for CPE. Cloud point extraction of $\mathrm{Cd}$ and $\mathrm{Pb}$ was performed in different $\mathrm{pH}$ buffer solutions; the effect of $\mathrm{pH}$ on the extraction recovery of $\mathrm{Cd}$ and $\mathrm{Pb}$ is shown in Figure 1. The extraction recovery was calculated based on the amount of analytes in the starting samples and in the surfactantrich solution after extraction. It can be seen that extraction was quantitative for $\mathrm{Cd}$ when the $\mathrm{pH}$ exceeded 5.0. For $\mathrm{Pb}$, the quantitative extraction was achieved in the $\mathrm{pH}$ range of 4.0 7.0. Hence, a pH of 6.0 was chosen as the compromise condition for subsequent work.

\section{Effect of PMBP Concentration}

A 10-mL solution containing $0.5 \mu \mathrm{g}$ of $\mathrm{Cd}$ and $\mathrm{Pb}$ in $1.0 \mathrm{~g} \mathrm{~L}^{-1} \mathrm{Tri}^{-}$ ton ${ }^{\circledR} \mathrm{X}-114$ and at a medium buffer of $\mathrm{pH} 6.0$ containing various amounts of PMBP was subjected to the cloud point extraction procedure. The extraction recovery as a function of the concentration of the PMBP is shown in Figure 2. As can be seen, the extraction recovery for $\mathrm{Cd}$ and $\mathrm{Pb}$ increased up to a PMBP concentration of $2.5 \times 10^{-4} \mathrm{~mol} \mathrm{~L}^{-1}$ and reaches near quantitative extraction. Thus, a PMBP concentration of $5.0 \times 10^{-4} \mathrm{~mol} \mathrm{~L}^{-1}$ was chosen to account for other extractable species that might potentially interfere with the assaying of $\mathrm{Cd}$ and $\mathrm{Pb}$.

\section{Effect of Triton X-114 Concen- tration}

A successful CPE maximizes the enrichment factor through minimizing the phase volume ratio. The variation in extraction efficiency of $\mathrm{Cd}$ and $\mathrm{Pb}$ within the Triton $\mathrm{X}-114$ concentration range of $0.1-2.0 \mathrm{~g} \mathrm{~L}^{-1}$ was examined and the results are shown in Figure 3. It can be seen that quantitative extraction was observed when the Triton X-114 concentration was above $0.8 \mathrm{~g} \mathrm{~L}^{-1}$. Therefore, a concentration of $1.0 \mathrm{~g} \mathrm{~L}^{-1}$ was chosen as the optimum surfactant concentration in order to achieve the highest possible enrichment factor.

\section{Effects of Equilibration Temper- ature and Time}

It was desirable to employ the shortest equilibration time and the lowest possible equilibration temperature as a compromise between completion of extraction and efficient separation of the phases. The dependence of extraction efficiency upon equilibration temperature and

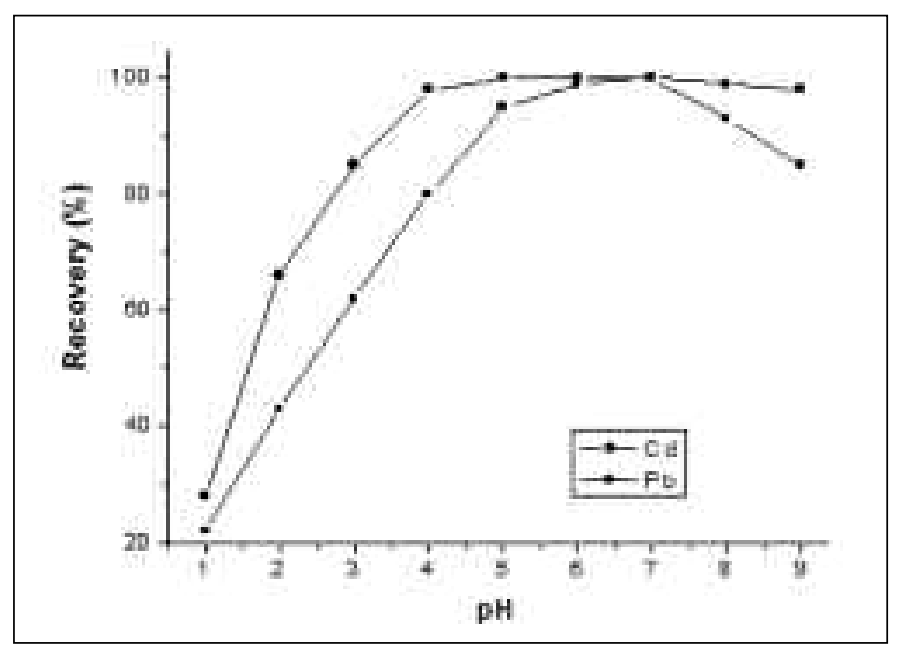

Fig. 1. Effect of $p H$ on the CPE extraction recoveries of $C d$ and $\mathrm{Pb}\left(0.5 \mu \mathrm{g} \mathrm{mL} \mathrm{L}^{-1} \mathrm{Cd}\right.$ and $\mathrm{Pb}, 5.0 \times 10^{-4} \mathrm{M} \mathrm{PMBP}, 1.0 \mathrm{~g} \mathrm{~L}^{-1}$ Triton $X-114)$.

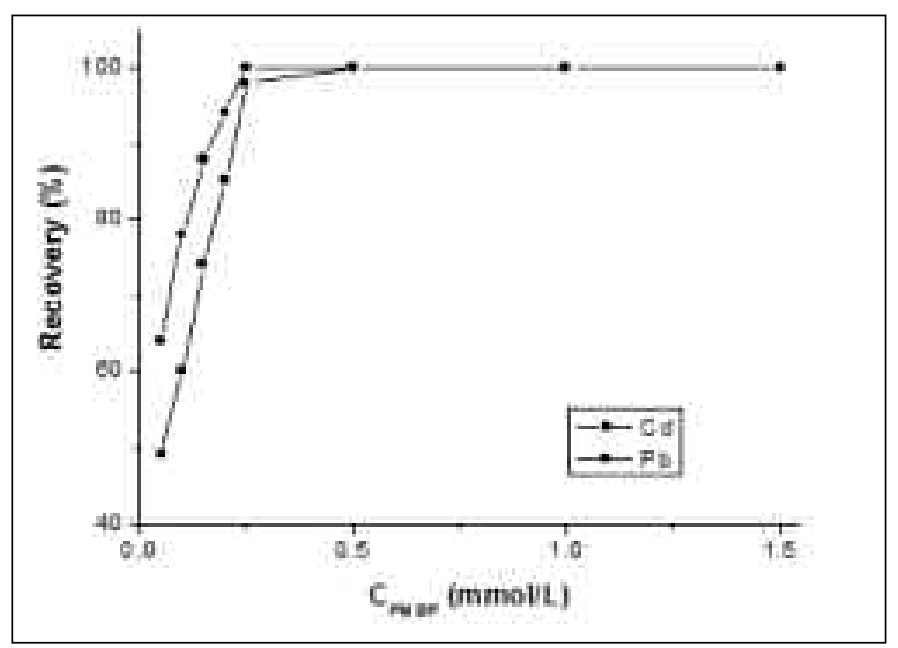

Fig. 2. Effect of PMBP concentration on the CPE extraction recoveries of $C d$ and $\mathrm{Pb}\left(0.5 \mu \mathrm{g} \mathrm{mL}^{-1} \mathrm{Cd}\right.$ and $\mathrm{Pb}, 1.0 \mathrm{~g} \mathrm{~L}^{-1}$ Triton $\mathrm{X}-114, \mathrm{pH}$ 6.O. 
time was studied ranging from 25 to $60^{\circ} \mathrm{C}$ and 5 to 30 minutes, respectively. The results showed that an equilibration temperature of $40{ }^{\circ} \mathrm{C}$ and a time of 15 minutes were adequate to achieve quantitative extraction.

\section{Interferences}

The potential interferences in the present method were investigated. The interferences were due to the competition of other heavy metal ions for the chelating agent and their subsequent coextraction with $\mathrm{Cd}$ and $\mathrm{Pb}$. In these experiments, solutions containing $0.1 \mu \mathrm{g} \mathrm{mL}^{-1}$ of $\mathrm{Cd}$ and $\mathrm{Pb}$ and the interfering ions were treated according to the recommended procedure. The tolerance limits of the coexisting ions, defined as the largest amount making the recovery of $\mathrm{Cd}$ and $\mathrm{Pb}$ less than 90\%, are listed in Table II. Large amounts of alkaline and alkaline earth metal ions showed no interferences with the CPE extraction of $\mathrm{Cd}$ and $\mathrm{Pb}$ under the selected conditions because of their very low stability constants of the PMBP complexes.

\section{Detection Limits and Precision}

According to the definition of

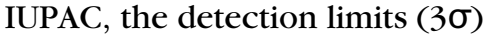
of this method were 0.83 and $1.48 \mathrm{ng} \mathrm{mL}^{-1}$ for $\mathrm{Cd}$ and $\mathrm{Pb}$ with relative standard deviations (RSD) of $2.7 \%$ and $3.8 \%$, respectively $(\mathrm{n}=11)$.

\section{Analytical Application}

To verify the accuracy of the proposed method, the concentrations of $\mathrm{Cd}$ and $\mathrm{Pb}$ in certified reference material NIST 1486 Bone Meal

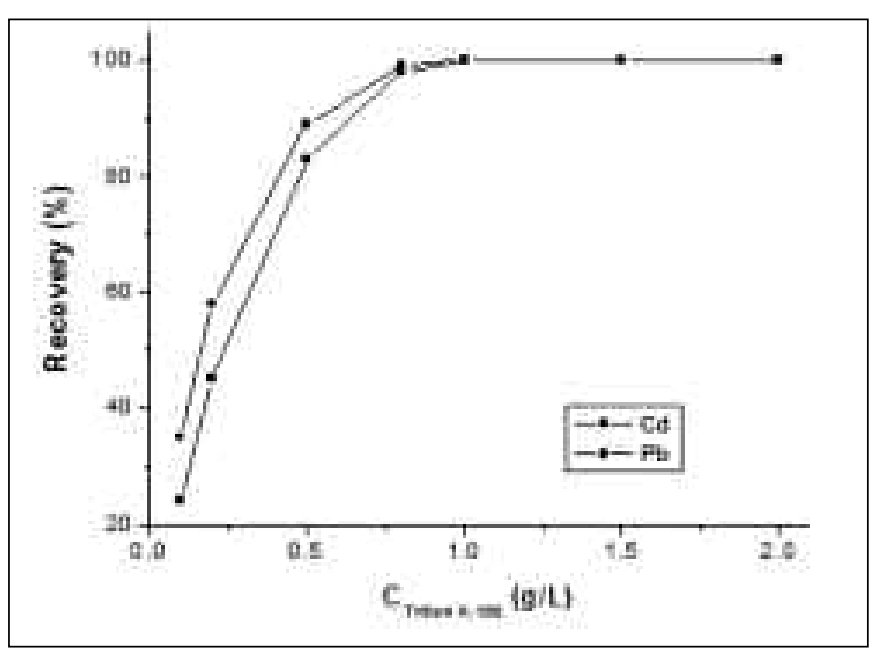

Fig. 3. Effect of Triton $X-114$ concentration on the CPE extraction recoveries of $C d$ and $P b\left(0.5 \mu g L^{-1} C d\right.$ and $P b$, $5.0 \times 10^{-4}$ M PMBP, pH 6.0).

TABLE II

Tolerance Limits of Coexisting Ions

$\begin{array}{lr}\text { Coexisting Ions } & \text { Tolerance Limits }\left(\mathrm{mg} \mathrm{L}^{-1}\right) \\ \mathrm{K}^{+}, \mathrm{Na}^{+}, \mathrm{Ca}^{2+}, \mathrm{Mg}^{2+} & 5000 \\ \mathrm{Cu}^{2+}, \mathrm{Co}^{2+}, \mathrm{Zn}^{2+}, \mathrm{Ni}^{2+}, \mathrm{Mn}^{2+} & 50 \\ \mathrm{Al}^{3+}, \mathrm{Cr}^{3+}, \mathrm{Fe}^{3+} & 10 \\ \mathrm{SO}_{4}{ }^{2-}, \mathrm{NO}_{3}, \mathrm{Cl}^{-} & 5000\end{array}$

were determined. As can be seen in Table III, the obtained results are in good agreement with the reference values.

The proposed method was applied to the determination of $\mathrm{Cd}$ and $\mathrm{Pb}$ in human teeth samples collected in Wuhan, P.R. China. In addition, the recovery experiments of different amounts of $\mathrm{Cd}$ and $\mathrm{Pb}$ were carried out; the results are shown in Table IV. Fairly good recoveries for the analytes were obtained ranging from 95-102\%, which are reasonable for trace analysis.

\section{CONCLUSION}

A new method of cloud point extraction (CPE) combined with inductively coupled plasma optical emission spectrometry (ICP-OES) has been proposed for the determination of $\mathrm{Cd}$ and $\mathrm{Pb}$ in human teeth samples. The method is simple, reproducible, and highly sensitive

TABLE III

Analytical Results of CRM NIST 1486 Bone Meal $\left(\mu \mathrm{g} \mathrm{g}^{-1}\right)$

\begin{tabular}{ccl}
\hline Element & Found $^{\mathrm{a}}$ & Certified Value $^{\mathrm{b}}$ \\
\hline $\mathrm{Cd}$ & $0.008 \pm 0.001$ & $(0.003)$ \\
$\mathrm{Pb}$ & $1.385 \pm 0.012$ & $1.335 \pm 0.014$
\end{tabular}

a The value following " \pm " was the standard deviations. $(n=3)$.

b The value in the parentheses is the non-certified concentration.

TABLE IV

Determination of $\mathrm{Cd}$ and $\mathrm{Pb}$ in Human Teeth Sample $\left(\mathrm{ng} \mathrm{g}^{-1}\right)$

\begin{tabular}{lccc}
\hline Element & Added & Found & Recovery (\%) \\
\hline $\mathrm{Cd}$ & 0 & $0.096 \pm 0.008$ & \\
& 0.2 & $0.292 \pm 0.016$ & 98 \\
& 0.5 & $0.605 \pm 0.029$ & 102 \\
$\mathrm{~Pb}$ & 0 & $3.74 \pm 0.18$ & \\
& 5.0 & $8.70 \pm 0.42$ & 99 \\
& 10 & $13.20 \pm 0.75$ & 95 \\
\hline
\end{tabular}


because of the distinct and advantageous features of CPE (in situ and single-step extraction). The surfactant-rich phase can be introduced into the nebulizer of the ICP-OES by conventional aspiration after dissolving with $0.1 \mathrm{~mol} \mathrm{~L}^{-1} \mathrm{HNO}_{3}$. The proposed method gives very low LODs (0.83 and $1.48 \mathrm{ng} \mathrm{mL}^{-1}$ for cadmium and lead), good relative standard deviations $(2.7 \%$ and $3.8 \%)$, respectively $(n=11)$, and can be applied to the determination of heavy trace metals in calcium-rich samples.

\section{ACKNOWLEDGMENT}

Financial support from the National Natural Science Foundation of China (No. 30300392) and the Fundamental Research Funds for the Central Universities of China (No. 3081019) is gratefully acknowledged.

$\overline{\text { Received January 29, } 2011 .}$

\section{REFERENCES}

1. G.F. Nordberg, B.A. Fowler, M. Nordberg, and L. Friberg, Handbook on the Toxicology of Metals, 3rd ed, Academic Press, Atlanta, USA (2007).

2. F.B. Pyatt, A.J. Pyatt, C. Walker, T. Sheen, and J.P. Grattan, Ecotox. Environ. Safe 60, 295 (2005).

3. F. Barbosa Jr, J.E. Tanus-Santos, R.F. Gerlach, and P.J. Parson, Environ. Health Perspect. 113, 1669 (2005).

4. H.M. Tvinnereim, R. Eide, and T. Riise, Sci. Total Environ. 255, 21 (2000).

5. J. Borkowska-Burnecka, A. Szymczycha-Madeja, and W. Zyrnicki, J. Hazard. Mater. 182, 477 (2010).

6. M. Grotti, M.L. Abelmoschi, S.D. Riva, F. Soggia, and R. Frache, Anal. Bioanal. Chem. 381, 1395 (2005).

7. G.C.Y. Chan and W.T. Chan, Spectrochim. Acta Part B 58, 1301 (2003).

8. A. Sanz-Medel, M.R. Fernandez de la Campa, E.B. Gonzalez, and M.L. Fernandez-Sanchez, Spectrochim. Acta Part B 54, 251 (1999).

9. F.H. Quina and W.L. Hinze, Ind. Eng. Chem. Res. 38, 4150 (1999).

10. A.E. Fernandez, Z.S. Ferrera, and J.J.S. Rodriguez, Analyst 124, 487 (1999).

11. R. Carabias-Martinez, E. RodriguezGonzalo, J. Dominguez-Alvarez, and J. Hernandez-Mendez, Anal. Chem. 71, 2468 (1999).

12. C.D. Stalikas, Trends Anal. Chem. 21, 343 (2002).

13. M.A. Bezerra, M.A.Z. Arruda, and S.L.C. Ferreira, Appl. Spectrosc. Rev. 40, 269 (2005).

14. S. Igarashi and K. Endo, Anal. Chim. Acta 320, 133 (1996).

15. M.F. Silva, L. Fernandez, R. Olsina, and D. Stacchiola, Anal.Chim. Acta 342, 229 (1997).

16. J.L. Manzoori and A.B. Tabrizi, Anal. Chim. Acta 470, 215 (2002).

17. J. Li, P. Liang, T.Q. Shi, and H.B. Lu, At. Spectrosc. 24, 169 (2003).

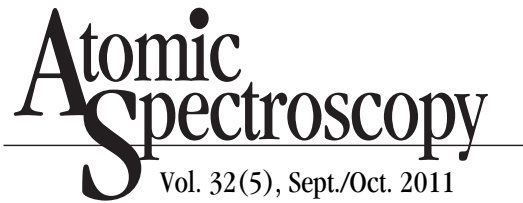

18. A.N. Tang, D.Q. Jiang, Y. Jiang, and X.P. Yan, J. Chromatogr. A 1036, 183 (2004).

19. P. Liang, Z.M. Sun, and J. Cao, At. Spectrosc. 28, 62 (2007).

20. E.L. Silva and P.S. Roldan, J. Hazard. Mater. 161, 142 (2009).

21. E. Ivanova, I. Havezov, N. Vracheva, and N. Jordanov, Fresenius J. Anal. Chem. 320, 133 (1985).

22. S. Umetani, S. Kihara, and M. Matsui, Anal. Chim. Acta 232, 293 (1990).

23. K. Benkhedda, E. Ivanova, and F. Adams, J. Anal. At. Spectrom. 14, 957 (1999).

24. P. Liang and X.G. Chen, Anal. Sci. 21, 1185 (2005). 